\title{
Catalytic Effects on Heat Transfer Measurements for Aerothermal Studies with $\mathrm{CO}_{2}$
}

\author{
Matthew MacLean ${ }^{*}$ and Michael Holden ${ }^{\dagger}$ \\ CUBRC, Aerothermal/Aero-optics Evaluation Center, Buffalo, NY, 14225
}

\begin{abstract}
An investigation has been performed at CUBRC using the LENS facilities to study the behavior of surface heating augmentation due to catalytic surface recombination for carbon dioxide and air test gases. Three types of heat transfer instrumentation have been employed on a model that shows definitive heating enhancement which can only be caused by the effect of surface catalysis. The measured heat transfer data from all types of instrumentation correlate well with CFD predictions in baseline non-catalytic flows, but show consistently higher heating levels than can be predicted with a non-catalytic wall in a catalytic environment. A similar effect has been documented in air with atomic oxygen and nitric oxide recombination. The successful demonstration and understanding of this behavior is critical to optimum heat shield/TPS systems design for future Martian entry applications.
\end{abstract}

\section{Introduction}

$\mathrm{R}^{\mathrm{s}}$ eliable payload delivery systems are necessary to deliver lander and rover payloads to other planets in the solar system in order to fulfill NASA's current planetary exploration directive, a primary focus of which is Mars. Although the costs and limited launch opportunities of such exploratory programs require that the re-entry vehicle have a high factor of safety to insure good odds of success, an overly conservative design will result in reduced payload and, hence, reduced scientific opportunity for the mission. Because the opportunities for flight tests in the Martian atmosphere are rare and the ability to collect data from such an experiment is typically limited or impossible, the optimization of heat shield design to insure robustness while minimizing unnecessary conservatism must be carried out in ground test facilities here on Earth.

A quantitative understanding of the heating augmentation caused by surface catalytic reactions on atmospheric re-entry bodies is essential for proper (efficient) heat shield and thermal protection system design. The effect of catalytic surfaces has been studied with regard to Earth entry on vehicles like the space shuttle and various re-entry capsules ${ }^{1}$. Unlike Earth, however, the Martian atmosphere is made up of about $95.7 \%$ carbon dioxide along with other trace chemicals ${ }^{2}$. While catalytic heating for Earth return missions can exist, the magnitude of such heating augmentation is generally small when compared to the potential catalytic effects of a carbon dioxide environment ${ }^{3}$. The large negative heats of formation of carbon dioxide and carbon monoxide along with the particular kinetics of carbon dioxide dissociation behavior in the shock layer create the potential for large levels of energy release on a catalytic surface.

In recent work on Martian entry bodies at CUBRC ${ }^{4}$, the effects of catalysis on the model was shown to be a central problem in making measurements of heating rates and transitional criteria in ground test measurements. Because of this issue, a unique program is being conducted at CUBRC in the LENS hypervelocity, shock tunnel facilities to make measurements in these catalytic carbon dioxide flows to assess the ability of a ground test program to understand and identify the heating response of the models in realistic, duplicated conditions appropriate to Martian entry. This effort is focusing centrally on understanding the aerodynamic heating response of robust model construction materials along with the response characteristics of various types of heat transfer instrumentation and how the choice of each affects the observed results. This effort consists of a tightly integrated combination of experimental measurements and numerical calculations targeted at understanding catalytic effects both on the ground and in flight. The long-term goal of this effort will be a capability at CUBRC to provide clear, reliable

\footnotetext{
${ }^{*}$ Senior Research Scientist, AIAA Member.

${ }^{\dagger}$ AAEC Program Manager, AIAA Fellow.

Copyright (C2006 by Matthew MacLean. Published by the American Institute of Aeronautics and Astronautics, Inc. (AIAA) with permission.
} 
ground test data for Martian entry applications that is relevant and appropriate to designing an optimum thermal protection system for future NASA missions to the red planet.

\section{Experimental Facility Background}

Currently, CUBRC operates the 48 " reflected shock tunnel, the LENS-I and LENS-II reflected shock tunnels ${ }^{5}$, and the LENS-X expansion tunnel ${ }^{6}$. The reflected shock tunnel uses a transient effect of an unsteady shock wave to heat a stagnant test gas to very high enthalpy levels for a short duration of time. This test gas may then be expanded through a converging-diverging nozzle in a manner similar to a blowdown facility to produce a hypervelocity test flow. Expansion tunnels like

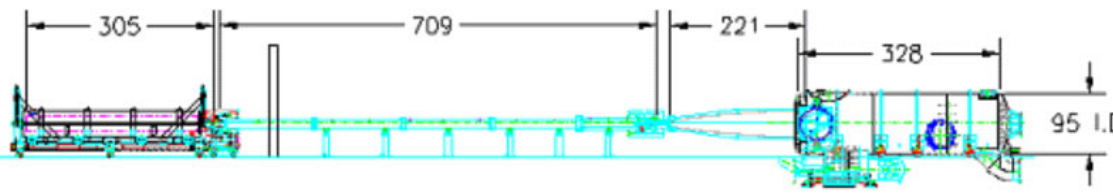

(a) LENS-I Facility

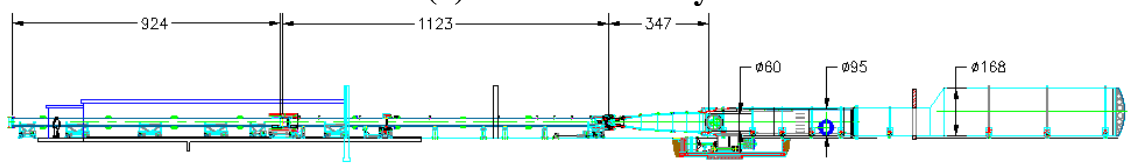

(b) LENS-II Facility

Figure 1. Drawings of CUBRC LENS Hypervelocity Reflected Shock Tunnel Facilities with Nominal Dimensions [all values shown in inches].

LENS-X also operate as short duration facilities, but an expansion tunnel produces a high enthalpy flow without the need to first stagnate the test gas. The result is a freestream flow that is free of frozen, dissociated chemical contamination that can plague reflected shock facilities at enthalpies exceeding $10 \mathrm{MJ} / \mathrm{kg}$. A schematic of LENS-I and LENS-II with basic length scales is given in Fig. 1.

The LENS reflected shock-tunnel facilities were developed primarily to study the full-scale, hypervelocity flow physics of interceptors and air-breathing engine configurations. The scale and flow duplication capabilities of LENS are such that these vehicles can be studied at their full scale, inclusive of effects such as transition to turbulence, turbulent mixing from cross-flow jets and thrusters, duplicated flow chemistry and other effects that are difficult or impossible to simulate at cold-flow or sub-scale conditions. Besides aerothermal measurements, extensive studies in this facility have been made using non-intrusive diagnostics such as aero-optic and aero-acoustic measurements, including recent work with tunable laser-diode diagnostics ${ }^{7}$. The capabilities of LENS-I duplicate the flight conditions of interceptors and scramjet engines from Mach 7 to 14 (with Reynolds number matching to Mach 20), while the LENS-II facility complements it in such a way that this capability is seamlessly extended down to Mach 3.5 at sea level density.

The facilities were designed with high-enthalpy air flows in mind, but it has been found that the facilities work well for a carbon dioxide test gas too. Although any of the three LENS facilities or the 48" tunnel can use carbon dioxide test gas with no special effort, LENS-I was used for all tests to date because it is most compatible with the primary goal of obtaining transition data on a $70^{\circ}$ sphere-cone model for the Mars Science Laboratory (MSL) program, with experimental testing sponsored by NASA Langley. The capability to use heated hydrogen for a driver gas in LENS-I provided transition data at the most relevant enthalpy for the Martian entry trajectory. The contoured D nozzle in LENS-I was

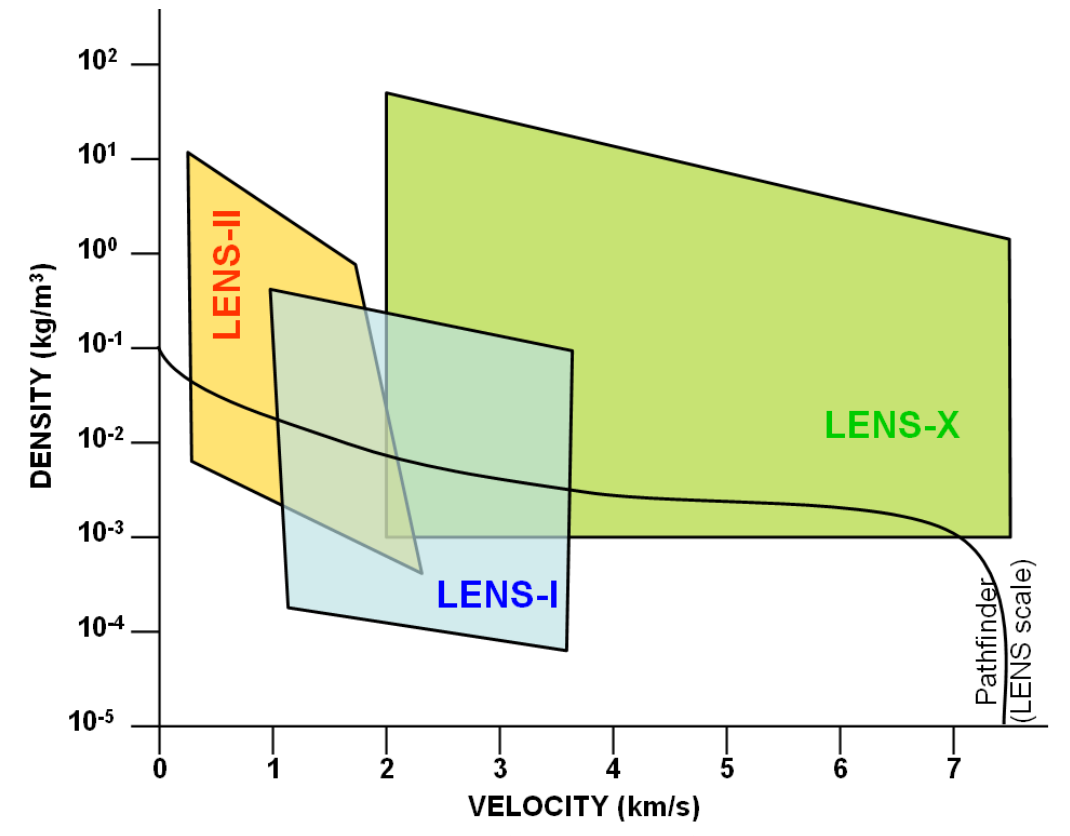

Figure 2. Density-Velocity Map of the CUBRC Facilities using Carbon Dioxide Test Gas 
found to produce reasonably uniform exit profiles with carbon dioxide without any modification using some of the existing throats, despite the fact that the slower expansion of carbon dioxide into the test section produces a lower Mach number than the same nozzle does for air at the same enthalpy. Sample results demonstrating the uniformity of the test core in carbon dioxide have already been shown ${ }^{4,8}$ and will not be repeated here. A typical capability map of density versus velocity is shown in Fig. 2 for carbon dioxide showing the three LENS facilities. The potential range of conditions, particularly for LENS-II and LENS-X, has been assessed analytically because the range of calibrated conditions are currently limited. A velocity-altitude graph for the Martian atmosphere was initially considered but was found to be uninteresting as the Martian atmosphere is so thin that all three facilities are capable of producing significantly higher than surface level densities. A typical entry trajectory is shown also from the Pathfinder mission ${ }^{9}$. The density of the trajectory has been increased to maintain a $(\rho L)$ simulation on a model scale that can fit conveniently in all three facilities, and the resulting trajectory has been found to fit well in the LENS capability range.

\section{Supporting Numerical Tools}

\section{A. DPLR Code}

All programs using the LENS facilities are extensively calibrated and validated with numerical tools. The primary CFD tool used in these efforts is the DPLR code provided by NASA Ames Research Center. DPLR is a multi-block, structured, finite-volume code that solves the reacting Navier-Stokes equations including finite rate chemistry and finite rate vibrational non-equilibrium effects. This code is based on the data-parallel line relaxation method $^{10}$ and implements a modified (low dissipation) Steger-Warming flux splitting approach ${ }^{11}$ for the convection terms and central differencing for the diffusion terms. Finite rate vibrational relaxation is modeled via a single vibrational degree of freedom ${ }^{12}$ using the Landau-Teller model ${ }^{13}$. Vibrational energy relaxation rates are computed by default from the semi-empirical expression due to Millikan and White ${ }^{14}$, but rates from the work of Camac ${ }^{15}$ are substituted where available for the $\mathrm{CO}_{2}-\mathrm{CO}_{2}$ collisions in the cases studied here. Transport properties are appropriately modeled in DPLR for this type of flow ${ }^{16,17}$ using the binary collision-integral based mixing rules from Gupta, et $\mathrm{al}^{18}$. Diffusion coefficients are modeled using the self-consistent effective binary diffusion (SCEBD) method $^{19}$. Turbulence models available in the DPLR code currently include the Baldwin-Lomax 0-equation model $^{20}$, the Spalart-Allmaras model 1-equation model ${ }^{21}$, and the Shear Stress Transport (SST) 2-equation model ${ }^{22}$ each with corrections for compressibility effects ${ }^{23,24}$.

\section{B. Catalytic Surface Modeling}

The issue of wall boundary condition deserves some specific consideration and DPLR is programmed with several options. The non-catalytic wall boundary condition provides the lowest level of surface heating. The supercatalytic boundary condition provides the highest possible level of heating because the mixture is returned to its lowest possible chemical energy state at the wall, meaning that the maximum amount of chemical energy has been returned to the other energy modes. In this case, that state corresponds to $100 \% \mathrm{CO}_{2}$. The super-catalytic boundary is non-physical in that it does not identify a specific mechanism by which the recombination occurs, but assumes that it has occurred by some unidentified process without consideration of rate mechanics. In the case of shortduration facilities like LENS, the surface temperature of the model never rises appreciably above room temperature, so the super-catalytic $\mathrm{CO}_{2}$ condition corresponds to a fully-accommodated chemical state.

The Mitcheltree wall catalysis model ${ }^{25}$ has been used in previous Mars entry vehicle designs. In the Mitcheltree model, $\mathrm{CO}_{2}$ production at the surface is essentially controlled by the oxidation of $\mathrm{CO}$ with atomic oxygen in an Eley-Rideal (E-R) reaction where either molecule has been adsorbed by the surface. Evaluation by Wright, et al. ${ }^{26}$ showed that the Mitcheltree model predicted catalytic heating rates that were only slightly higher than the corresponding non-catalytic rates. This is largely due to the fact that, with the conditions produced in both the LENS-I and T5 facilities, the bulk of the oxygen is trapped in the form of $\mathrm{O}_{2}$ molecules (not atoms). The Mitcheltree model was generally found to be unable to predict the level of heating found in the tests of the MSL configuration in $\mathrm{CO}_{2}$ in $\mathrm{LENS}^{27}$ and the related test program in the CalTech $\mathrm{T} 5$ tunnel $^{26}$.

Adequate prediction of observed ground test, cold wall heating levels therefore requires a

$$
\begin{gathered}
()_{S}+C O \Leftrightarrow(C O)_{S} \\
()_{S}+O_{2} \Leftrightarrow(O)_{S}^{1}+(O)_{S}^{2} \\
(O)_{S}^{1}+(C O)_{S} \Leftrightarrow C O_{2}+()_{S} \\
(O)_{S}^{2}+(C O)_{S} \Leftrightarrow C O_{2}+2()_{S}
\end{gathered}
$$


catalysis model in which molecular oxygen participates in the conversion of $\mathrm{CO}$ into $\mathrm{CO}_{2}$ at the surface. Such a mechanism was previously identified by Wright, et al. from the literature database in the automotive catalytic converter community. The work of Bonzel and $\mathrm{Ku}^{28}$, for instance, demonstrated the catalytic reaction of $\mathrm{CO}$ and $\mathrm{O}_{2}$ on a Platinum surface. Additional work from the catalytic converter community has identified similar mechanisms on other precious metals such as Palladium ${ }^{29}$ and Ruthenium ${ }^{30}$. Further searching of the literature has revealed that the work of Jenkins and Voisey ${ }^{31}$ did indeed identify a catalytic effect particular to stainless steel. Their experimental measurements suggest that $\mathrm{O}_{2}$ occupies a single adsorbed site on the steel surface and the oxidation of CO occurs as part of a two step Langmuir-Hinshelwood (L-H) reaction between the adsorbed and dissociated oxygen atoms with adsorbed CO molecules. This mechanism is repeated in Eqns. (1) - (4). The rates of this mechanism were made on 18/8 stainless steel, but Jenkins and Voisey presumed that the results would be generally applicable to any stainless alloy. It is still unclear if this is the reaction mechanism that is active in ground tests like those in the LENS facility, but it is consistent with much of the observed behavior of the measurements.

\section{Previous Experimental Results}

Previous measurements in carbon dioxide test gas for the MSL program studied a $70^{\circ}$ sphere-cone model that was $61 \mathrm{~cm}$ (24") in diameter constructed of a stainless-steel shell. Surface heating instrumentation consisted primarily of thin-film gages set individually into the surface as buttons in the stainless-steel surface. More complete discussion of the heat transfer gage instrumentation will be given in the next section. A series of tests were completed in the LENS-I facility primarily at an enthalpy level of $5 \mathrm{MJ} / \mathrm{kg}$ with the primary objective to obtain data on transition and turbulent heating over the model, particularly on the leeward side of the vehicle at the anticipated flight angle of attack of $11^{\mathrm{O}}$. This objective was fulfilled, and subsequent publication $^{4}$ of the results identified the two main issues with regard to ground testing of the MSL aeroshell as catalytic effects on the model and transition effects on the model. Using the measured heat transfer data both on and off the centerline of the model, it was clear that these two effects both contributed to an increase in heating over the baseline non-catalytic laminar level, so that a separation of these two effects required careful, independent study.

A summary of the measured heating data at $11^{\mathrm{O}}$ angle of attack on this model is shown in Fig. 3. A single prediction from DPLR has been provided for the lowest Reynolds number case (run 7) where laminar flow is most likely to persist without transitional heating effects. The DPLR solutions for the two extreme surface boundary conditions have been plotted, where the non-catalytic wall predicts the minimum heat transfer rate. On the leeward side, it appears that run 7 does remain laminar over the whole face of the model to the corner, but the measured heat rates correspond almost exactly to the predicted super-catalytic level. The other runs at higher Reynolds numbers display proportional levels of heating caused by transition onset, but there is always at least

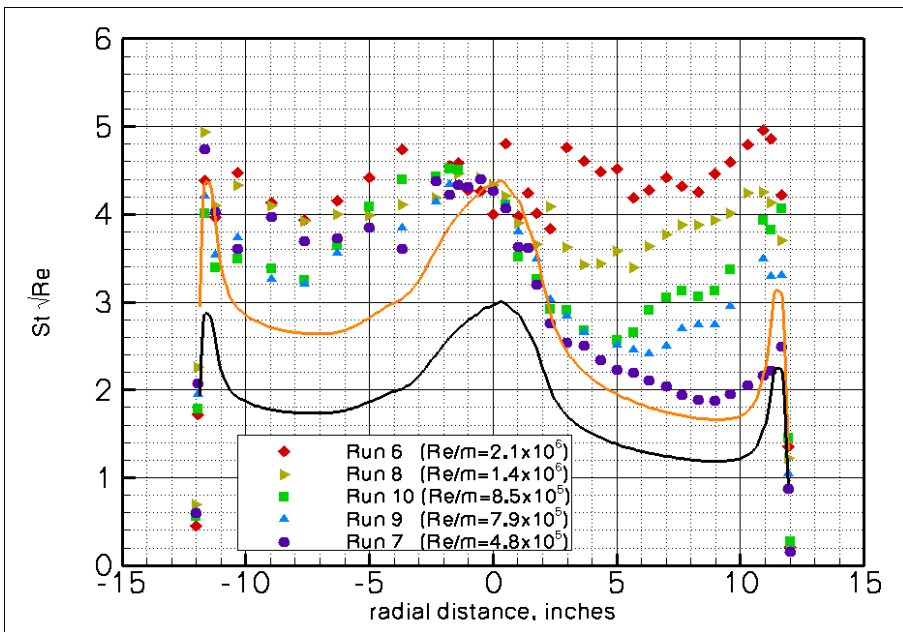

Figure 3. Previously Measured Non-dimensional Heat Transfer on Sphere-Cone Model at ${ }^{\circ}{ }^{\circ}$ Angle of Attack for a Range of Reynolds Numbers ${ }^{4}$

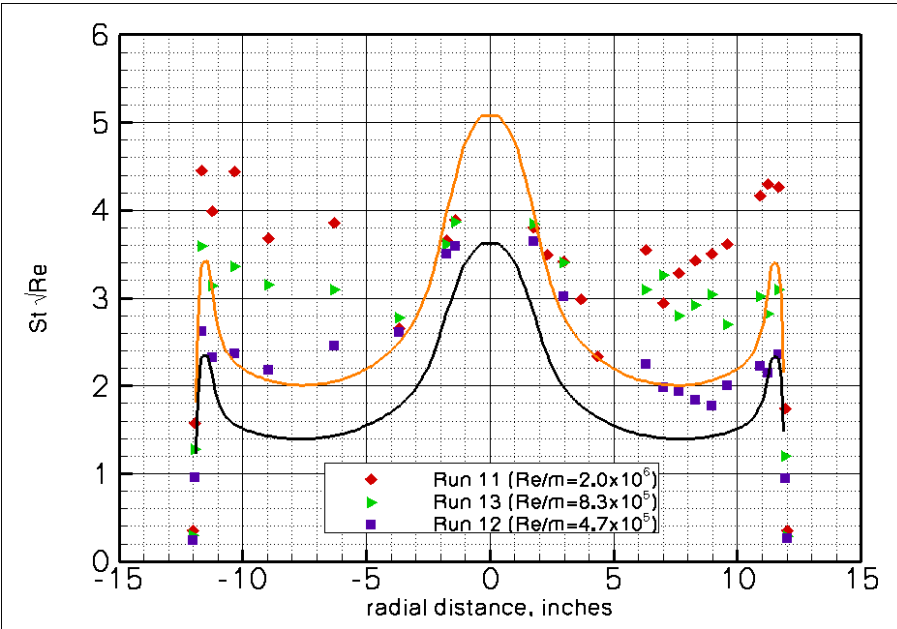

Figure 4. Previously Measured Non-dimensional Heat Transfer on Sphere-Cone Model at $0^{\mathbf{O}}$ Angle of Attack for a Range of Reynolds Numbers ${ }^{4}$ 
some length of laminar heating at the nose that corresponds to the super-catalytic prediction. On the windward side, apparent windward transition behavior makes a comparison difficult to make.

A similar study was made at $0^{\circ}$ angle of attack as shown in Fig. 4. This series of three runs was made last, so by this point in the program much of the delicate thin-film instrumentation had been eliminated by particulate damage, particularly in the nose region. In context, obtaining thin-film data for thirteen runs in a shock tunnel facility is actually far more than would typically be expected. This problem is typical of all shock tunnel facilities, but steps are taken in LENS to protect the model and minimize particle damage. Again, a set of solutions using DPLR for the lowest Reynolds number condition is given. Without instrumentation in the nose, it is impossible to make an assessment of the catalytic behavior of the data, but the indications farther outboard of the model are that the measured data displays the same character of super-catalytic recombination on the surface, releasing maximum energy to the model. At the higher Reynolds numbers, transition was again obtained in the outboard part of the surface explaining the departures above the super-catalytic, laminar level.

\section{Instrumentation/Model}

Because of the two sources of uncertainty identified with regard to surface heating on a $70^{\circ}$ sphere-cone in carbon dioxide in the ground tests, a second phase model was constructed and instrumented. The primary purpose of the construction and testing of this new model was to verify and understand the transition behavior on both the windward and leeward sides of the model. Because the phase one study in the LENS-I facility produced such turbulent flows on the model and no completely laminar solution was obtained on the model at angle of attack, a half-scale model was chosen with a $30.5 \mathrm{~cm}$ diameter (12") to make it easier to generate a fully laminar flow. The transition data obtained will not be discussed further here. However, because of its importance in understanding and isolating the heating augmentation caused by transition, the effect of catalytic heating on the model was considered as a secondary objective in this new phase of the program. To facilitate this study, a more complete suite of instrumentation was installed on this second generation model. CUBRC has the ability to use heat transfer instrumentation of several types in the LENS shock-tunnel facilities. Pictures of these types of instrumentation are shown in Fig. 5.

The first type of instrumentation used is the thin-film gage, shown in Fig. 5(a). It is the type employed most commonly in LENS testing. Essentially, the construction of a thin-film gage consists of a pocket of a thermally insulating material - commonly Pyrex or Macor. A tiny strip of platinum is painted on the surface of the insulator. The platinum strip acts as a resistance thermometer to measure the surface temperature history of the insulator, which may be considered to have an infinite thermal boundary on the backside because of the low conductivity. Because the platinum strip is so small, it contributes negligible heat capacity to the insulator. A one-dimensional heat conduction equation is used to translate the surface temperature history into heating rate. Gages as small as 1 $\mathrm{mm}(0.040$ ") diameter are routinely employed in LENS testing. There are two primary advantages of this type of instrumentation, both of which result from the small size of the gage. First, the small size of the platinum strip makes it the most sensitive and accurate of any type of instrumentation available. Second, the small size allows for a very spatially localized measurement to be made in a region of high gradient heating. A good example of the application of these gages is shown in the recent tests of the NASA Shuttle Orbiter ascent configuration ${ }^{32}$, where tiny, scaled bipod feet on the main tank were constructed by CUBRC technicians from Macor and instrumented with approximately 40 individual thin-film gages each to obtain unprecedented localized heating rates on each facet of the bipod foot region. The main disadvantage of this type of instrumentation is its fragility, as evidenced in the first phase of MSL testing. The tiny, exposed platinum strip is sensitive to any minute impact from particulate. LENS employs a centerbody valve system in all the tunnels that closes off the shocktube as soon as the data is acquired to minimize the amount of particulate that enters the test section, but it is impossible to stop all of it. 
Additionally, there are two subtypes of thin-film gages that vary in the method of construction. In the first application, sometimes called a "button," the insulating substrate is constructed in a round form factor and inserted flush into the metallic wall of the model. Thus, the gage is an island of Pyrex on the metal surface. In this case, there will be a certain running length of metallic surface upstream and downstream of the button gages, creating a discontinuity in the surface composition. This could potentially create a "jump" effect in the catalytic behavior of the measurement by a boundary layer moving across two surfaces of differing catalysis. The thin-film gages on the phase one model were of this type, so it was unclear at the time whether a catalytic jump effect could be causing the elevated heat transfer rates measured on the model. An alternate method of thin-film construction is to place the gages on a continuous surface of Pyrex. This arrangement is sometimes called a "strip" or "ladder" gage. In this case, there is no metallic surface between the gages, with the idea being that the continuous insulating surface will avoid any catalytic jump effect. However, for both the button and the ladder gages, there is a strip of platinum exposed to the flow. As the catalytic effect of platinum is known to be significant in both nitric oxide and carbon monoxide $^{28}$, the effect of this exposure on the high speed flow is unclear.

The second type of instrumentation used at CUBRC is the chromel/constantan coaxial thermocouple gage, which also measures the surface temperature history of the metallic model. This is shown in Fig. 5(b). The thermocouple is inserted flush to the wall, forming a continuous surface of metallic compounds with no gaps. The advantage of the coaxial gage is that it is far more robust than the thin-film gage and it is the best choice for test programs in very harsh environments. However, the uncertainties in the measurement are over twice those found when employing thin-film gages. Also, the physical size of the thermocouples requires somewhat more space than the thin-film so there are limitations on the localization of heating measurements.

The third type of heating instrumentation is the calorimeter gage, shown in Fig. 5(c). The calorimeter gage at CUBRC is constructed from a block of silver completely isolated from the surrounding model in an insulating sleeve. A thin-film type resistive thermometer is placed on the back side of the silver block and the temperature history is monitored there. Because of the exceptionally high conductivity of silver, surface heat transmitted to the calorimeter is quickly spread to the back side at the measurement location. The accuracy of the back side measurement is similar to the thin-film gage, but the advantage to this arrangement is that the fragile thin-film strip is sheltered and protected from particulate in the flow. This feature makes the silver calorimeter much more robust than a thin-film gage for harsh applications.

In order to assess catalytic behavior in a carbon dioxide flowfield, gages of all three types were installed on the phase two model, shown in Fig. 6. First, a thin-film strip of 16 gages was placed on a continuous Pyrex insert to avoid the potentially discontinuous effect of the buttons seen in the phase one model. Second, a row of coaxial thermocouples were placed from the stagnation point outward in opposing directions so that both windward and leeward data would be collected at angle of attack.

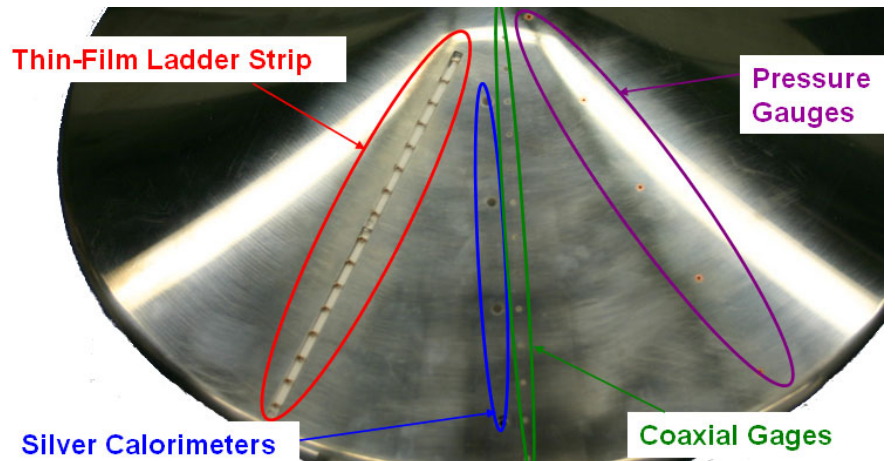

Figure 6. Phase Two Model with Installed Heat Transfer Instrumentation

Finally, four silver calorimeter gages were placed alongside the thin-films and coaxial rays at evenly spaced radial 
locations. The idea behind the design of the model was that the robust coaxial gages would be used as the primary tool to acquire transition data at angle of attack, and the other - more accurate - instrumentation would be used to help assess the catalytic behavior of the coaxial gages during the first few runs before the attrition of the thin-film gages.

In terms of quality and character of the traces from the measurements, a sample time-dependent trace of heat transfer is shown from a typical run from the program in Fig. 7. A gage of each type was picked in proximity to each other in a transitional region near the outer edge of the model. In this transitional region, experience in the shock tunnels has shown that the intermittency of the turbulent flow will show up in the traces in the form of highfrequency oscillations that will average to some median value between laminar and turbulent heating extremes. From Fig. 7, this character is apparent in all three traces. The thin-film gage, with the smallest thermal mass of the three types, will pick up this behavior the best. The silver calorimeter gage, with its large thermal mass was initially expected to dampen this high frequency data, but a simple calculation of the properties of the gage showed that the resonance time of the silver is on the order of a few microseconds. Therefore, the silver calorimeter should be capable of recognizing heating changes from time-varying phenomena up to that timescale. The correct intermittency behavior is captured in this case.

\section{Catalytic Surfaces in Air Flows}

Before investigating the effects of catalytic heating in carbon dioxide flows in the LENS facilities, a case is considered on a blunt body in air at nominally $5 \mathrm{MJ} / \mathrm{kg}$ enthalpy. At this enthalpy level, there is some chemical dissociation in a stagnating flow, and, therefore, a possibility of catalytic heating augmentation on a catalytic surface. As part of a study of NO concentration measurements in the freestream of the LENS-I facility ${ }^{7}$, a two-dimensional cylinder model was installed in the test section as shown in Fig. 8. This cylinder is $8.68 \mathrm{~cm}$ in diameter (3.47") and has an aspect ratio of approximately $5: 1$. Near the center of the cylinder where end effects may be considered negligible are parallel rows of button-type thin-film gages and coaxial gages starting at the stagnation point and at regular angles around the cylinder. A third row starting at the stagnation point contains a series of surface pressure gages.

Because a reflected shock tunnel stagnates the flow in the reservoir before expanding the flow into the test section, significant levels of nitric oxide are generated at enthalpy levels of $3.5 \mathrm{MJ} / \mathrm{kg}$ and above. Some percentage of this is frozen during the expansion process in the nozzle. From an equilibrium mass fraction of $8.9 \%$ in the LENS-I reservoir, a CFD calculation with finite-rate chemistry recombination predicted a nitric oxide mass fraction residual of $5.9 \%$ in the test section freestream. This result indicates that $3.6 \%$ of the total enthalpy of the flow is trapped in frozen chemical energy, which will produce a non-equilibrium flowfield in the shock layer of the cylinder. As proof of the accuracy of the freestream conditions predicted by the CFD
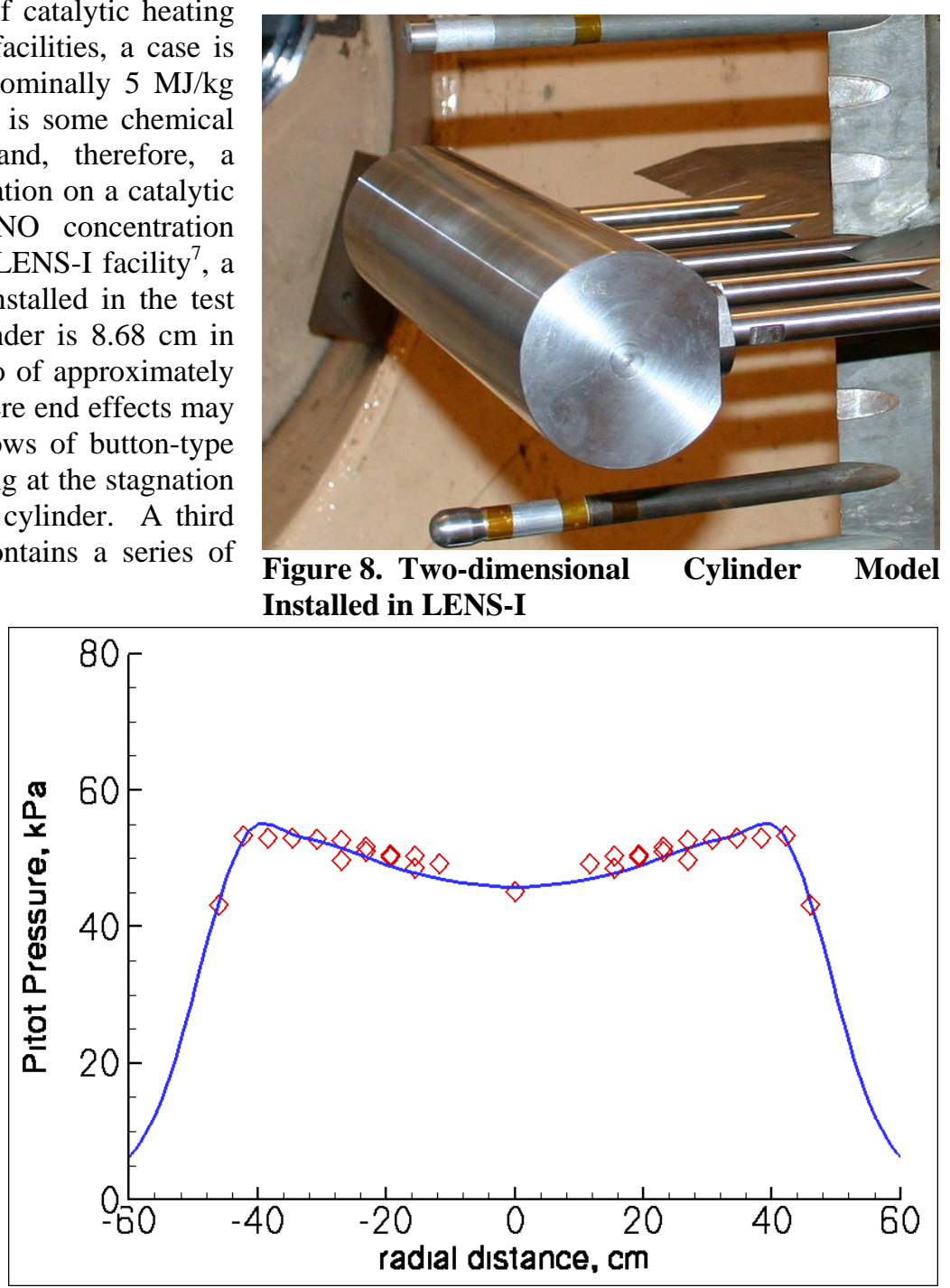

Figure 9. Comparison of Predicted and Measured Pitot Pressure Profile for a $5 \mathrm{MJ} / \mathrm{kg}$ Run with Air in the LENS-I Facility 
solution, the profile of Pitot pressure is considered as measured in the freestream. This comparison is shown in Fig. 9. The Pitot pressure shows sensitivity to both the chemical energy relaxation and the vibrational relaxation. The excellent agreement at the centerline (where the cylinder is located) along with the correct trends and test core size predicted by the numerical simulation provides confidence that the freestream conditions are known accurately.

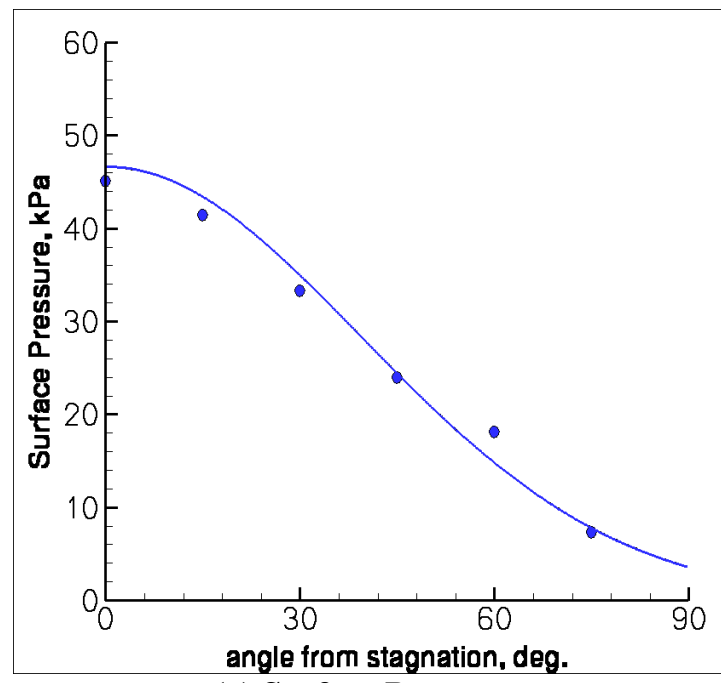

(a) Surface Pressure

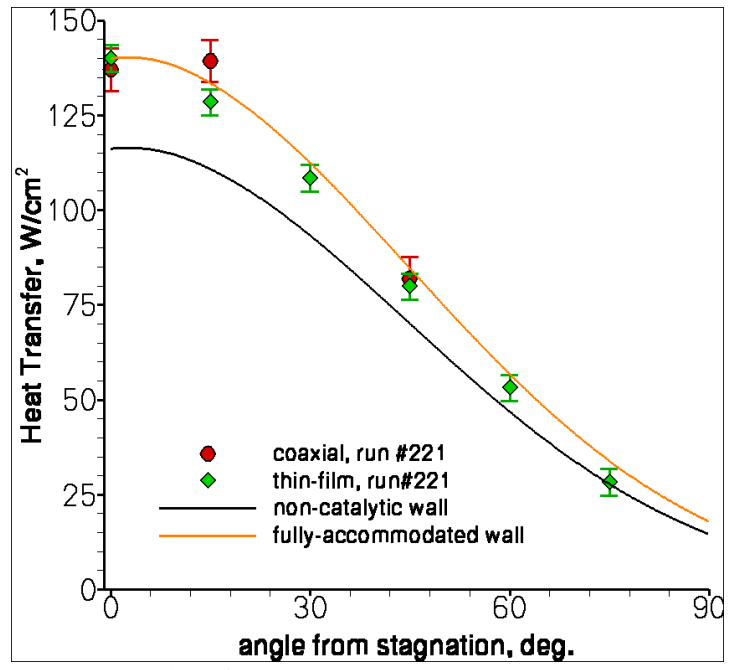

(b) Surface Heat Transfer

Figure 10. Comparison of Predicted and Measured Surface Quantities on Two-dimensional Cylinder Model at $5 \mathrm{MJ} / \mathrm{kg}$ in Air

With an accurate prediction of Pitot pressure in the flowfield, it is logical to expect a similar level of accuracy of surface pressure on the model. This comparison is shown in Fig 10(a) and, as expected, is accurate to within the accuracy of the measurements. The comparison of surface heat transfer on the model is shown in Fig. 10(b), which shows two limiting prediction cases - one for a non-catalytic wall and one for a fully recombined (super-catalytic) wall. Also shown are the rows of both thin-film gages and coaxial gages with error bars on each gage type. From this, two things are apparent. First, at points where a gage of both types is available, the levels measured by the thin-film and the coaxial gages are nominally the same. Second, these measured levels are consistent with the super-catalytic boundary condition, particularly at the stagnation point where the heating rate is most important. Even with error bars on the data, a non-catalytic wall cannot explain the measured level of heating. Further querying of the DPLR solution with the non-catalytic wall boundary condition shows that the surface at the stagnation line has a mixture of both nitric oxide (NO) and atomic oxygen (O), indicating that a fully-accommodated wall must fully catalyze both of these species. Previous work has shown a catalytic effect with oxygen recombination that is specific to shock tunnel instrumentation ${ }^{34-36}$, so it is presumed that there is a similar mechanism for nitric oxide as well.

This sample case demonstrates that even in air flows it can sometimes be necessary to account for catalytic effects on blunt bodies in ground testing. This case was selected because of the extensive history of CUBRC and its predecessor Cornell Aeronautical Laboratory (CAL) in shock tunnel ground tests with air. The 48" tunnel, for example, has made nearly 10,000 runs. This experience lends credibility to the understanding of the flowfield conditions and the dynamics of the facilities using air as a test gas that the limited database of tests in carbon dioxide cannot.

\section{Results on the $70^{\circ}$ Sphere-Cone Model}

\section{A. Results in Perfect Gas Nitrogen Flow}

Initially, a single case in nitrogen was run in the LENS-I facility before testing with carbon dioxide began. Nitrogen is a well-understood gas in the CUBRC reflected shock tunnels, so a single case was used to check the performance of the instrumentation, verify the gage calibrations, and verify the model setup. The model was installed at $0^{\mathrm{O}}$ angle of attack so the flowfield is axisymmetric. Conditions were selected to produce a low enthalpy, low pressure flow so that the nitrogen would behave as a perfect gas. Freestream conditions are as follows: $\mathrm{U}=2,579 \mathrm{~m} / \mathrm{s}, \mathrm{h}_{0}=3.50 \mathrm{MJ} / \mathrm{kg}, \mathrm{Re} / \mathrm{m}=9.6 \times 10^{5}, \mathrm{~T}=159 \mathrm{~K}, \rho=4.525 \times 10^{-3} \mathrm{~kg} / \mathrm{m}^{3}, \mathrm{~T}_{\mathrm{VIB}}=2,300 \mathrm{~K}$. The flow is $100 \%$ 
molecular nitrogen as there is no dissociation of the gas. There is, however, a large frozen vibrational energy component in the flow. This is a well-known result of the slow vibrational relaxation of nitrogen during the expansion process in a reflected shock tunnel. Since DPLR includes the capability to model vibrational nonequilibrium, the case does not present any special difficulties.

This case was used in an initial study of the impact of grid resolution on the solutions. Both two-dimensional and three-dimensional grids have been considered. The sphere-cone shape presents certain well-known numerical difficulties because of the bluntness of the shape. A poorly constructed grid will result in large scale irregularities in the computed heat transfer, which can occur in both two-dimensional and three-dimensional grids. Fitting the grid to the bow shock of the sphere-cone helps to alleviate these issues. The newest version of DPLR includes a built-in grid adaptation capability that was used for these cases shown here. Additionally, two-dimensional grids can be adversely affected by the singularity boundary at the axisymmetric axis. For an axisymmetric flowfield like run 1, it is obviously advantageous to use a two-dimensional grid to obtain a quicker result. However, the singularity-free three-dimensional grid will usually produce the smoothest result, so the potential penalty in solution accuracy must be weighed against the computing time advantage for a two-dimensional grid.

The two-dimensional grid is a single-block grid of the model forebody with the singularity boundary at the centerline. At the finest grid level, the grid is 512x256 cells which have been sequenced by two, four, and eight. The predicted heat transfer for this run on those grids is shown in Fig. 11. Of the four solutions, the coarsest is clearly not adequate as it is not even in the range of asymptotic convergence. The influence of the singularity boundary is slightly evident near the stagnation point on all grids. The solutions on the three-dimensional grids are shown in Fig. 12. Here, the heat transfer prediction is smoothest without the singularity boundary at the stagnation point. Also, the coarsest solution is again not adequate to capture the solution. On both the two-dimensional and three-dimensional grids, however, the stagnation point heating is consistent at the finest two respective grid level to within $2 \%$ or less. Very fine near-wall spacing was required to obtain the asymptotic convergence on these grids, with a distance of the first point from the wall approximately $0.5 \mu \mathrm{m}$ at the finest grid level in both two and three dimensions.
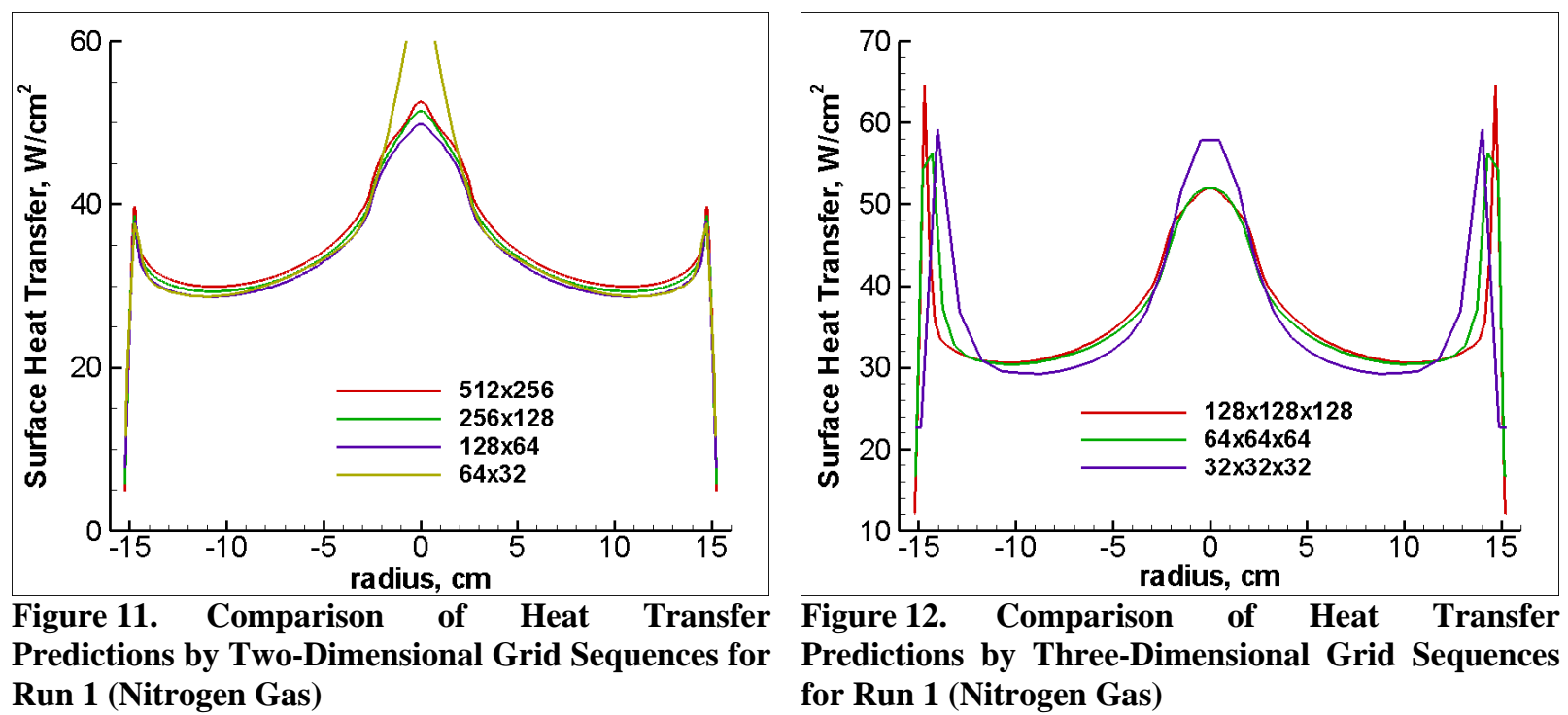

Having demonstrated grid independence of the numerical solutions in both two and three dimensions, the finest grid levels are compared to the experimental data from run 1 in Fig. 13. In terms of the experiment, the important thing to note is that all three types of heat transfer gages measure the same value of heat transfer within their respective uncertainties where a comparison can be made. Comparing the two numerical solutions together from the two-dimensional grid and the three-dimensional grid shows the effect of the singularity boundary clearly with this selection of grids. This effect is observable, but is not particularly significant except in terms of aesthetics. Further investigation of this two-dimensional effect has shown that a two-dimensional grid that is extracted as a slice from a three-dimensional grid will produce the same heat transfer prediction as its three-dimensional counterpart despite the inclusion of the singularity ${ }^{33}$. Thus, it is possible to generate a smooth two-dimensional solutions with DPLR if enough time and care is exercised in grid construction and fitting. Comparison of the two solutions at the stagnation point shows that they predict the same heating value to less than $1 \%$. Comparing the predictions to the measured data shows good overall agreement. The stagnation point heating is correctly captured by the predictions 
and any differences are generally small - on the order of $10 \%$ or less. Finally the comparison of the predicted with the measured pressure on the model is shown in Fig. 14. The excellent comparison of the pressure data helps to verify the freestream conditions of the facility.

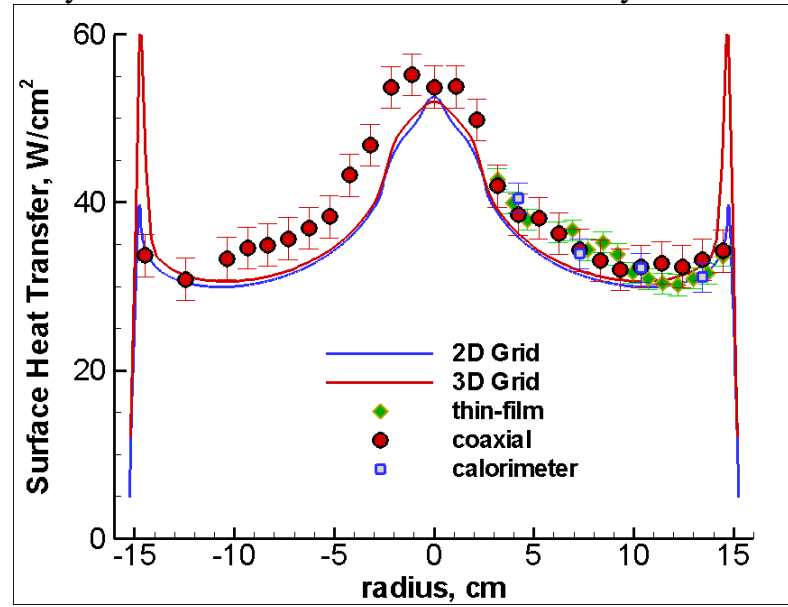

Figure 13. Comparison of Measured Surface Heat Transfer with Numerical 2D and 3D Predictions for Run 1 (Nitrogen Gas)

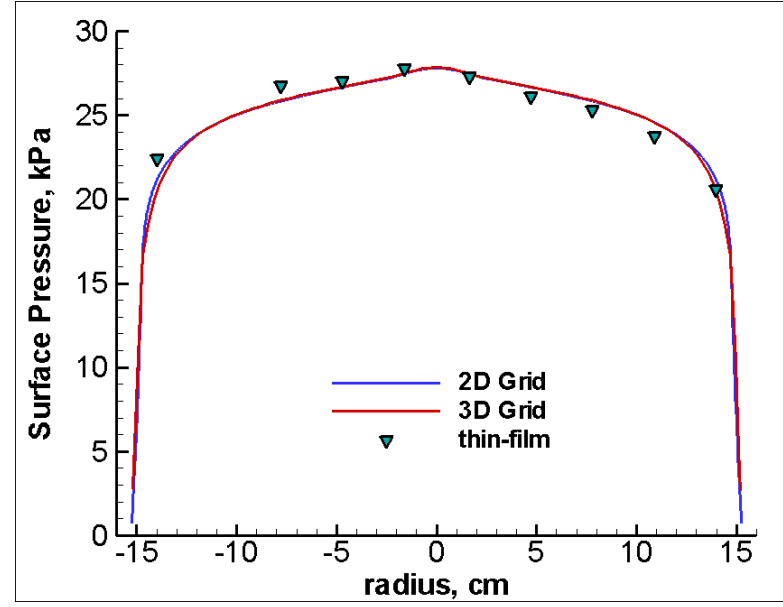

Figure 14. Comparison of Measured Surface Prressure with Numerical 2D and 3D Predictions for Run 1 (Nitrogen Gas)

This analysis of grid dependency and comparison with the experimental data is important when considering the effects of catalysis in the cases of high enthalpy $\mathrm{CO}_{2}$. This case has shown that the predictions can capture the heating data on this model to within nominally $10 \%$ even including ordered discretization effects and freestream uncertainty. The effect of the catalytic heating in $\mathrm{CO}_{2}$ is much larger than this and can be on the order of a factor of two. Thus, the comparison with the non-catalytic and super-catalytic predictions will be significant in looking at the catalytic data.

\section{B. Comparison of Instrumentation Response in Carbon Dioxide}

Because transition was the primary objective in this test series, the first few runs in carbon dioxide were performed at the flight angle of attack of $11^{\mathrm{O}}$. Although the study of catalytic effects was done primarily at $0^{\mathrm{O}}$ angle of attack to facilitate analysis by generating an axisymmetric flowfield, those runs did not appear until later in the test program. By that point, most of the sensitive thin-film gages had been eliminated by particulate damage. A comparison of the response by the various types of gages employed on the model has been performed using run 2 even though it was an angle of attack run. The angle of attack complicates the flowfield slightly, but does not preclude accurate analysis of the heat transfer response. Freestream conditions for this run have been estimated to be: $U=2,844 \mathrm{~m} / \mathrm{s}$, $\left(\mathrm{h}_{0^{-}}\right.$ $\left.\mathrm{h}_{\mathrm{W}}\right)=6.0 \mathrm{MJ} / \mathrm{kg}, \quad \mathrm{Re} / \mathrm{m}=2.54 \times 10^{5}, \quad \mathrm{~T}=$ $\mathrm{T}_{\mathrm{VIB}}=795 \mathrm{~K}, \quad \rho_{\mathrm{CO} 2}=2.32 \times 10^{-3} \mathrm{~kg} / \mathrm{m}^{3}$, $\rho_{\mathrm{CO}}=4.10 \times 10^{-4} \mathrm{~kg} / \mathrm{m}^{3}, \quad \rho_{\mathrm{O} 2}=2.30 \times 10^{-4} \mathrm{~kg} / \mathrm{m}^{3}$, $\rho_{\mathrm{O}}=2.1 \times 10^{-6} \mathrm{~kg} / \mathrm{m}^{3}$.

At this enthalpy level, there are significant mass fractions of dissociated species in the shock layer of the sphere-cone model. For the non-catalytic wall, DPLR predicts the following mass fraction at the stagnation point of the model: $\mathrm{c}_{\mathrm{CO} 2}=0.714, \quad \mathrm{c}_{\mathrm{CO}}=0.182$, $\mathrm{C}_{\mathrm{O} 2}=0.086, \mathrm{c}_{\mathrm{O}}=0.018$. The main conclusion

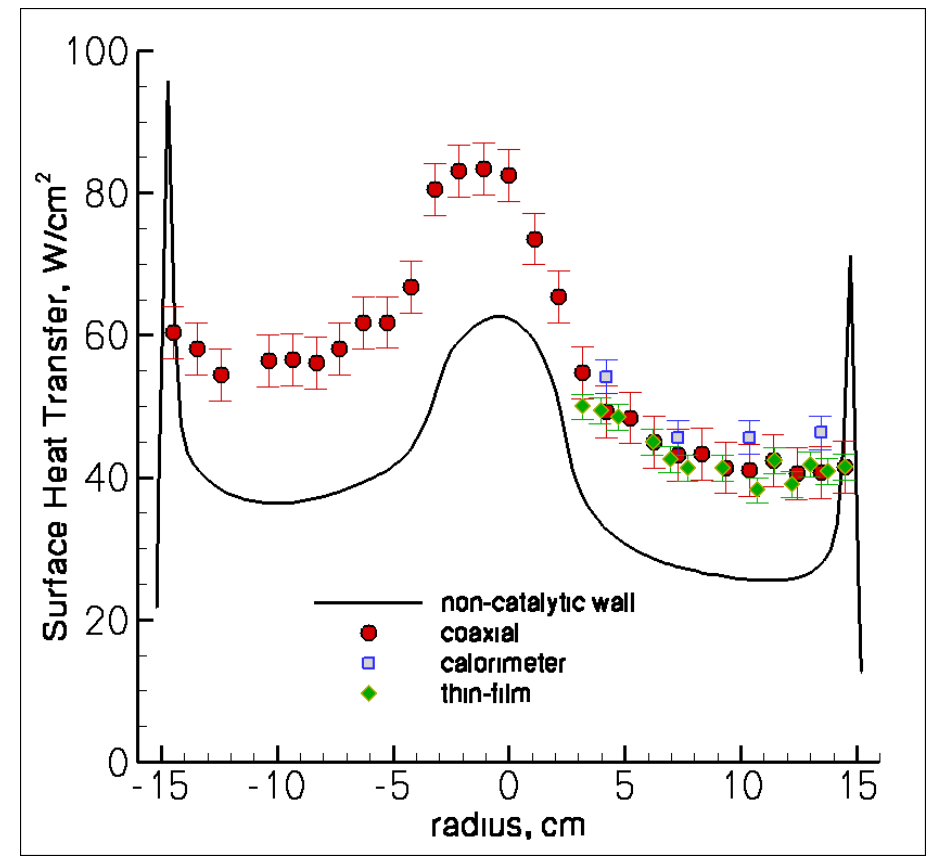

Figure 15. Comparison of Surface Heat Transfer Measurements for Run 2 with Different Types of Instrumentation 
from this case is that all three types of instrumentation measure exactly the same level of heat transfer in a catalytic flowfield. This value is significantly higher than the non-catalytic wall prediction, and approaches the fullyaccommodated (super-catalytic) wall condition. This will be discussed more fully in the next section.

The coaxial gages feature exposed chromel and constantan (which are metallic compounds). The calorimeter gage has exposed silver, which is known to be a very catalytic material in laboratory tests. The thin-film gages are on a seamless strip of pyrex, except for small platinum strips at the location where the measurement is made. The pyrex is expected to be generally non-catalytic. It is unclear whether the small amount of platinum generates the observed wall catalysis at the measurement location. However, the net result of the thin-film construction is that it is consistent with the response of the silver and the coaxial gages. Also, the catalytic behavior of the thin-film gages on the ladder strip is consistent with the results seen from the button gages in the phase one model as well as the other gages in this model on a ray consisting of a continuous metallic surface. Thus, we can detect no evidence of a catalytic jump effect in this flowfield. It appears that the effect of the thin-film gage is to measure a genuinely catalytic heat transfer level.

\section{Comparison of Catalytic Effects in Carbon Dioxide with Changes in Total Enthalpy}

Finally, a series of tests were performed in the LENS facility by setting the model at zero degrees angle of attack to generate an axisymmetric flowfield. The shock speed was increased by using different driver gas mixtures to increase the total enthalpy of the flow in steps to assess the effects of wall catalysis on the measurements. These measurements are compared with the DPLR predictions in this section. Again, the primary focus of this test series was to obtain transition data on the MSL forebody shape, so the axisymmetric catalytic runs were inter-mixed with transition runs at various angles of attack to avoid compromising the acquisition of the transition data. The summary of the freestream conditions for these runs is given in Table 1. The change in enthalpy was achieved by changing driver gas composition while maintaining nominally the same driver pressure. This resulted in an increase in shock speed (thus total enthalpy) while keeping stagnation pressure low enough to minimize the effects of transition.

\begin{tabular}{|c|c|c|c|c|c|c|c|c|}
\hline \multicolumn{2}{|c|}{ Table 1. Freestream Condition Set for $\mathbf{C O}_{2}$ Run Sequence } \\
\hline \multirow{2}{*}{$\begin{array}{c}\text { Run } \\
\#\end{array}$} & $\mathbf{h}_{\mathbf{0}}-\mathbf{h}_{\mathbf{W}}$ & $\mathbf{P}$ & $\mathbf{T}$ & $\mathbf{U}$ & $\rho_{\mathbf{C O} 2}$ & $\rho_{\mathbf{C O}}$ & $\rho_{\mathbf{O} 2}$ & $\rho_{\mathbf{O}}$ \\
\cline { 2 - 9 } & $M J / \mathrm{kg}$ & $P a$ & $K$ & $\mathrm{~m} / \mathrm{s}$ & $\mathrm{kg} / \mathrm{m}^{3}$ & $\mathrm{~kg} / \mathrm{m}^{3}$ & $\mathrm{~kg} / \mathrm{m}^{3}$ & $\mathrm{~kg} / \mathrm{m}^{3}$ \\
\hline $\mathbf{1 6}$ & 1.89 & 1,010 & 361 & 1,908 & 0.01478 & 0.00001 & 0.00001 & 0.00000 \\
\hline $\mathbf{8}$ & 5.63 & 1,614 & 893 & 2,871 & 0.00773 & 0.00078 & 0.00045 & 0.00000 \\
\hline $\mathbf{1 2}$ & 5.99 & 1,535 & 925 & 2,937 & 0.00687 & 0.00081 & 0.00046 & 0.00000 \\
\hline $\mathbf{1 3}$ & 8.65 & 1,482 & 1,116 & 3,374 & 0.00416 & 0.00121 & 0.00067 & 0.00002 \\
\hline
\end{tabular}

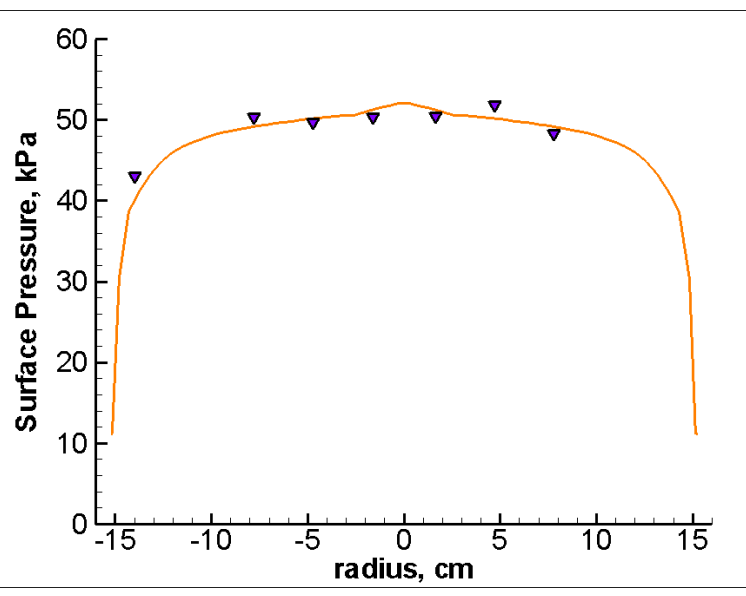

(a) Surface Pressure

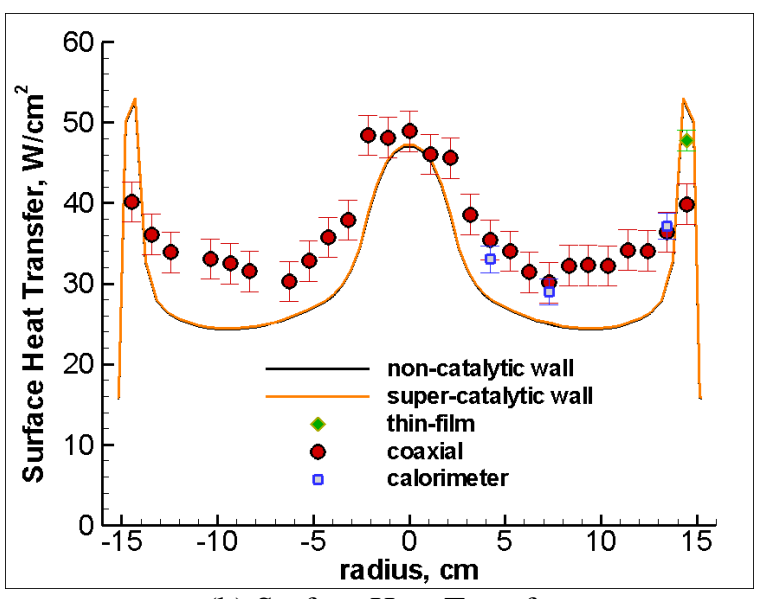

(b) Surface Heat Transfer

Figure 16. Comparison of Measured Surface Heat Transfer and Pressure with Numerical Predictions for Run 16

The runs are considered in the order of increasing total enthalpy. First, shown in Fig. 16, is the comparison of pressure and heat transfer for run 16 at a relative enthalpy of $1.9 \mathrm{MJ} / \mathrm{kg}$. Run 16 employed a mixture of nitrogen and helium driver gases. At this enthalpy, there is a small amount of vibration energy (equilibrium) in the $\mathrm{CO}_{2}$ gas, but there is no significant dissociation either in the reservoir of the facility or in the shock layer of the model flowfield. 
Because there is no dissociation, there is no catalytic heating for this case. This is confirmed in Fig. 16(b), where the DPLR solutions for both wall boundary conditions produce indistinguishable heating curves. Comparison with the data shows good overall agreement with the measurements. Effort was made to keep the Reynolds number low enough to prevent transition on the zero degree angle of attack, but the total pressure recovery is much higher for this cold condition (given the same driver gas pressure) than it is at higher enthalpies. Thus, this cold run displays some transitional behavior on the outboard part of the model, explaining the sudden change in curvature in heating at a radius of $8 \mathrm{~cm}$ and beyond. In the range of zero to $8 \mathrm{~cm}$, however, agreement in heating is generally within about $10 \%$ or so of the measurement, which is reasonable given the summation of measurement error, freestream condition prediction error, and numerical solution errors. The pressure in Fig. 16(a) also helps verify that the freestream conditions are reasonable as the pressure measurements are well-captured across the face of the model.

At higher enthalpies, the effect of wall catalysis becomes more apparent. The results from run 8, with a pure helium driver gas, are shown in Fig. 17. Here, there is a significant catalytic effect predicted by DPLR with heat transfer for the super-catalytic wall boundary condition nearly a factor of two above the non-catalytic wall at the stagnation point. Comparison with the measured data shows some unintuitive trends. As before with the phase one model, the non-catalytic wall boundary cannot predict the level of heating on any gage from stagnation point to the corner. In general, most of the individual gages compare well with or are just below the super-catalytic solution prediction. The exceptions are the three gages located at the stagnation point and immediately to either side of it. For these three gages, the measured heat transfer is clearly at an intermediate level between the two CFD solutions, possibly indicating a finite-rate catalytic recombination at the stagnation point. Although there are only coaxial gages located in this region of the model, the good agreement in the cases previously shown between the different types of instrumentation provides confidence that these measurements are good. Additionally, the pressure data is well-predicted.

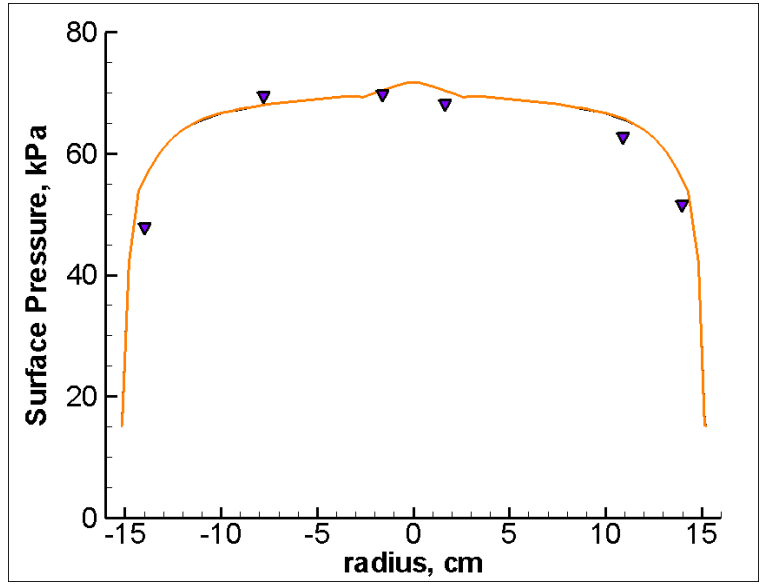

(a) Surface Pressure

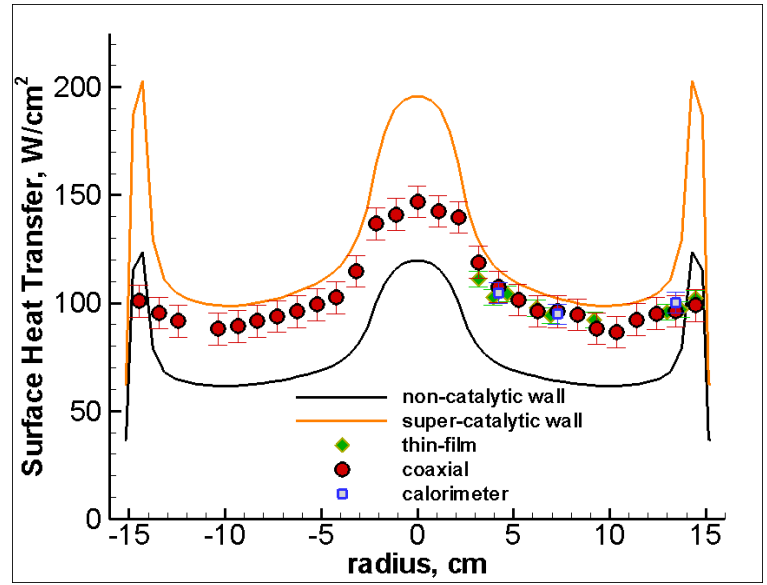

(b) Surface Heat Transfer

Figure 17. Comparison of Measured Surface Heat Transfer and Pressure with Numerical Predictions for Run 8

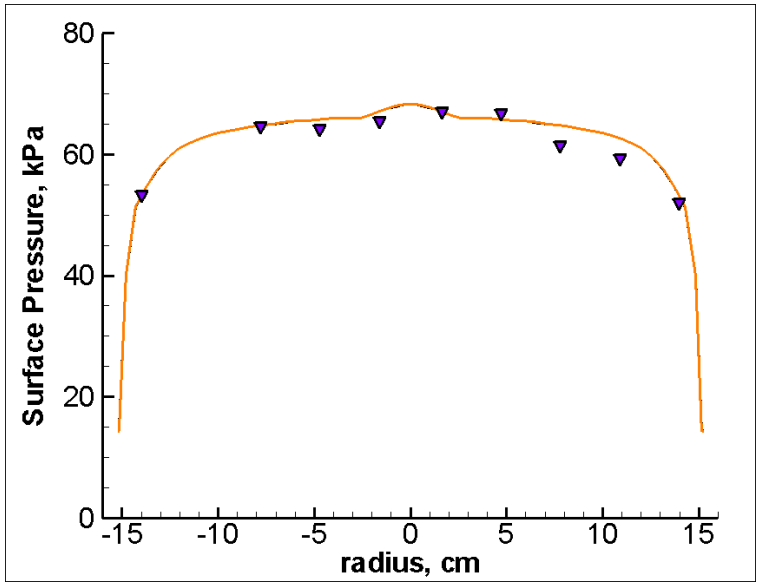

(a) Surface Pressure

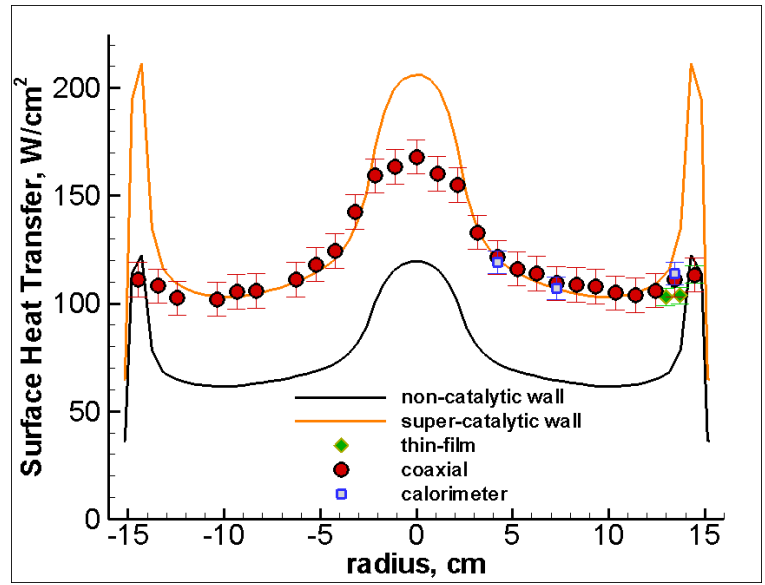

(b) Surface Heat Transfer

Figure 18. Comparison of Measured Surface Heat Transfer and Pressure with Numerical Predictions for Run 12 
For run 12, a mixture of helium and hydrogen driver gas was employed. The design of this experiment was to create an enthalpy level significantly higher than for run 8 but significantly lower than for a purely hydrogen driver gas. However, the effective tailoring of the facility was such that the total enthalpy of this run was only slightly higher than for run 8. The comparison with the measured surface data is shown in Fig. 18. Figure 18(b) shows the same heat transfer trends that were seen for run 8 . The gages, both coaxial and calorimeter, show agreement with the super-catalytic solution everywhere except for the three gages in the stagnation region. Furthermore, an interesting comparison may be made by comparing the experimental data from run 12 in Fig. 18(b) with the experimental data from run 8 in Fig. 17(b). The freestream conditions for the two runs are very similar, with slightly more enthalpy for run 12. This is reflected in the measured heat transfer, with a measured stagnation value of 147 $\mathrm{W} / \mathrm{cm}^{2}$ for run 8 and $168 \mathrm{~W} / \mathrm{cm}^{2}$ for run 12 . With the high-enthalpy $\mathrm{CO}_{2}$ test series, there has been concern with the possibility of driver gas contamination of the test gas. A measurement of freestream heat transfer rate does not directly imply any information about driver gas contamination, but the consistency of the surface measurements for two different driver gas compositions does give some indication that the driver gas is not a strong influence on the model. Just as with run 8, surface pressure is predicted well.

Finally, the comparison of the DPLR solutions for run 13 is shown in Fig. 19. Here, the trend seen thus far is not preserved. Looking first at the pressure in Fig. 19(a), agreement here is not as good as it was for the other runs, but the comparison is within about 7\%, which is probably indicative of uncertainty in the freestream conditions at this high enthalpy level. Looking at the heat transfer comparison in Fig. 19(b), the data falls at most half way between the non-catalytic and super-catalytic predictions. At all points, the non-catalytic wall is unable to predict a sufficiently high heating level to match the data. This conclusion is unchanged. However, the super-catalytic prediction significantly over-predicts the heat transfer. It is unclear how much of this difference between the predictions and the measurement is due to uncertainty in the freestream, but a crude, heuristic look at uncertainty in the freestream suggests that freestream uncertainty is NOT likely to fully explain the differences between the conclusions at this enthalpy level and those at the lower enthalpy levels. Based on this, it seems that there is finiterate catalytic reaction at all points on the surface. More measurements need to be made - particularly at this tunnel operating condition - to fully understand these results.

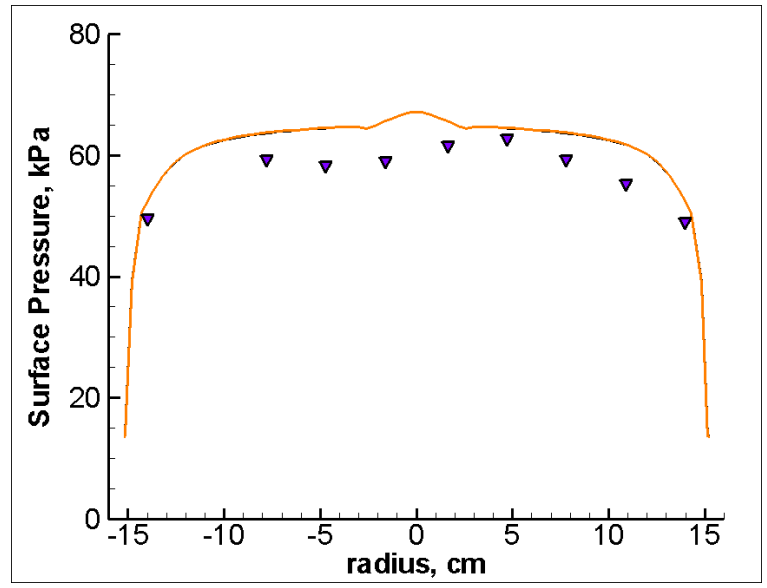

(a) Surface Pressure

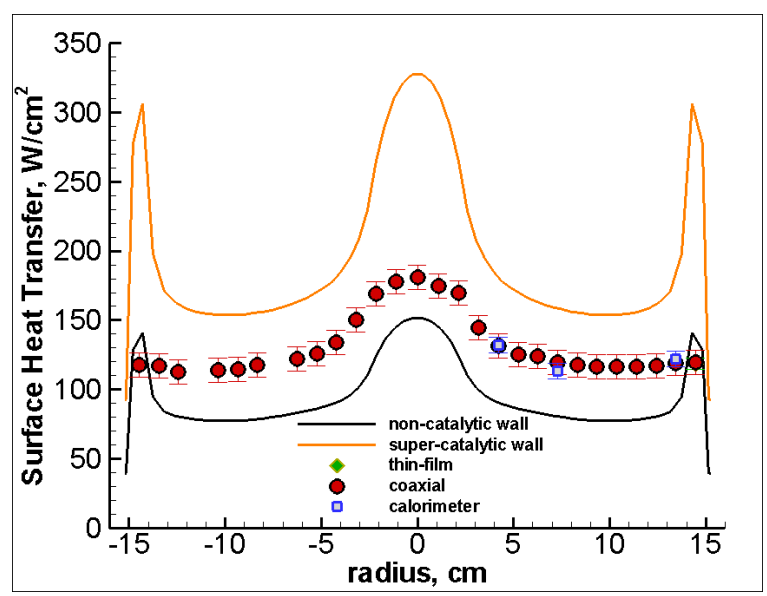

(b) Surface Heat Transfer

Figure 19. Comparison of Measured Surface Heat Transfer and Pressure with Numerical Predictions for Run 13

\section{Conclusions}

Given the results presented here there is clearly a need for additional study of this problem, so a few notes about the future direction of this research program is appropriate at this point. A review of the literature on catalytic heating effects in hypersonic ground testing revealed some activity in the early part of the 1960's, primarily at Cornell Aeronautical Laboratory and Aerospace Corporation. In the work of Myerson ${ }^{34}$, the catalysis of atomic oxygen was studied using RF energy to partially dissociate a slow molecular oxygen flow and the short duration effects of that flow were studied on stagnation heat transfer probes similar to the current thin-film technology employed by CURBC. Hartunian and Thompson ${ }^{35}$ employed a similar technique using a glow-discharge shocktube, which combined the effect of RF energy dissociation that was timed to dissociate the flow behind a normal shock in a shocktube. This approach is attractive because a shocktube apparatus may be used to simulate conditions that are 
more representative of those encountered in a shock tunnel facility than a static test would. Also, the RF application may be timed such that the heat transfer probe sees a short duration of non-dissociated flow followed immediately by a short duration of dissociated flow. Under this set of conditions, a probe sensitive to catalytic heating should show a sudden increase in the heat transfer measured at the midpoint of the run. A non-catalytic probe would measure the same level of heating both before and after the RF energy application. Both studies were successful in isolating a catalytic heating effect with atomic oxygen in this manner. This technique provides a clean, direct method to demonstrate catalytic response on actual heat transfer instrumentation. Some initial investigation has been made into this technique, and it seems likely that the method can be adapted to test probes for exposure to carbon dioxide flows also. A tentative plan to make this measurement is underway.

An equally interesting result from the literature is that these studies employed a coating of silicon monoxide ( $\mathrm{SiO}$ ), which apparently protected the heat transfer gages from the effects of catalysis, rendering the probe completely non-catalytic to oxygen and nitrogen atomic flows by blocking all the adsorbed sites on the surface of the probe ${ }^{36}$. Since carbon monoxide must react with an adsorbed oxygen atom to recombine on the surface also, it may be that silicon monoxide will protect a probe against this source of heating augmentation also. This coating will be tested to see its effect, although the utility of this coating may be limited if it cannot withstand the harsh shock tunnel environment for any length of time. Still, a coated non-catalytic probe might be useful to establish baseline heating, calibrate the catalytic gages, etc.

Many questions remain to be resolved in this area. It is hoped that some of them will be addressed with the techniques discussed in this section along with additional measurements from the facilities. The following conclusions have been drawn so far from this study:

- Studies from both the phase one and phase two models have consistently shown measured heating rates that are significantly higher than that predicted by CFD solutions employing the non-catalytic wall boundary condition.

- Three types of instrumentation measure exactly the same level of heating in catalytic carbon dioxide flows despite differences in construction and exposed materials.

- The measurements studied to date have not shown any evidence of a catalytic jump effect. The similar behavior displayed by both button-type and ladder-type thin-film gages and their consistency with all-metal gages suggests that the heating increase is, most likely, not due to catalytic jump.

- The similarity in the measured heat transfer levels for two runs with nominally similar freestream conditions but different driver gas mixtures provides some indirect evidence that the LENS-I facility is not being compromised by driver gas contamination.

- Some evidence has been collected to suggest that the catalytic surface reactions are finite-rate and do not reach their equilibrium point for some conditions that seems to depend on model size, shocklayer chemistry, and flow velocity (enthalpy).

- Cases in non-dissociated nitrogen and carbon dioxide that have only a convective heating component do show good correlation between prediction and theory.

- Catalytic behavior of the instrumentation has been demonstrated in moderate enthalpy air in a flowfield environment that is well-understood. Heat transfer measurements for this case corresponded exactly to fully-accommodated, cold-wall surface chemistry.

Additional measurements, particularly at the highest enthalpy level $(9-10 \mathrm{MJ} / \mathrm{kg})$ must be made. We will employ the numerical capabilities of DPLR and advanced experimental techniques - particularly tunable-laser diode measurements of species concentrations - to continue to assess the performance of the instrumentation for applications to ground test modeling of Martian atmospheric entry. 


\section{References}

${ }^{1}$ Scott, C. "Effects of Nonequilibrium and Wall Catalysis on Shuttle Heat Transfer”. Journal of Spacecraft and Rockets. Vol 22, no 5. Pgs 489 - 499. Sept - Oct 1985.

${ }^{2}$ Park, C.; Howe, J.T.; Jaffe, R.J.; and Candler, G.V. "Review of Chemical-Kinetic Problems of Future NASA Missions II: Mars Entries”. Journal of Thermophysics and Heat Transfer. Vol 8, no 1. Pgs 9 - 23. 1994.

${ }^{3}$ Paterna, D.; Monti, R.; Savino, R.; and Esposito, A. "Experimental and Numerical Investigation of Martian Atmosphere Entry”. Journal of Spacecraft and Rockets. Vol 39, no2. Pgs 227 - 235. March - April 2002.

${ }^{4}$ MacLean, M.; Wadhams, T.; Holden, M.; and Hollis, B. "Investigation of Blunt Bodies with $\mathrm{CO}_{2}$ Test Gas including Catalytic Effects”. AIAA Paper 2005 - 4693. 38 ${ }^{\mathrm{TH}}$ AIAA Thermophysics Conference, Toronto, CA: 6 - 9 June 2005.

${ }^{5}$ Lu, F.K. and Marren, D.E. Eds. Advanced Hypersonic Test Facilities. AIAA Progress in Astronautics and Aeronautics Series: Vol 198. Chapter 4. Reston, VA: American Institute of Aeronautics and Astronautics, 2002.

${ }^{6}$ Holden, M.S.; Wadhams, T.P.; and Candler, G.V. "Experimental Studies in the LENS Shock Tunnel and Expansion Tunnel to Examine Real-Gas Effects in Hypervelocity Flows”. AIAA Paper 2004-0916. January 2004.

${ }^{7}$ Parker, R.; Wakeman, T.; Holden, M.; and MacLean, M. "Measuring NO Freestream Concentration Using Quantum Cascade Lasers at CUBRC”. AIAA Paper 2006-0926. $44^{\mathrm{TH}}$ Aerospace Sciences Meeting \& Exhibit. Reno, NV: 9-12 January 2006.

${ }^{8}$ MacLean, M.; Candler, G.; and Holden, M. "Numerical Evaluation of Flow Conditions in the LENS Reflected ShockTunnel Facilities”. AIAA Paper 2005-0903. 43 ${ }^{\mathrm{RD}}$ Aerospace Sciences Meeting \& Exhibit. Reno, NV: 10-14 January 2005.

${ }^{9}$ Spencer, David; Blanchard, Robert; Thurman, Sam; Braun, Robert; Peng, Chia-Yen; and Kallemeyn, Pieter. "Mars Pathfinder Atmospheric Entry reconstruction”. AAS 98-146. AAS/AIAA Space Flight Mechanics Meeting, Monteray, CA. 9-11 February 1998.

${ }^{10}$ Wright, M.J.; Bose, D.; and Candler, G.V. “A Data Parallel Line Relaxation Method for the Navier-Stokes Equations”. AIAA Journal. Vol 36, no 9. Pgs 1603 - 1609. Sept 1998.

${ }^{11}$ MacCormack, R.W. and Candler, G.V. "The Solution of the Navier-Stokes Equations Using Gauss-Seidel Line Relaxation”. Computers and Fluids. Vol 17, No 1. Pgs 135 - 150. 1989.

${ }^{12}$ Candler, G.V. “Chemistry of External Flows”. Aerothermochemistry for Hypersonic Technology: Von Karman Institute for Fluid Dynamics Lecture Series. VKI LS 1995-04.

${ }^{13}$ Landau, L. and Teller, E. “Theory of Sound Dispersion”. Physikalische Zeitschrift der Sowjetunion. Vol 10, no 34.1936.

${ }^{14}$ Millikan, R. and White, D. "Systematics of Vibrational Relaxation”. Journal of Chemical Physics. Vol 39, no 12. Pgs 3209 - 3213. 1963.

${ }^{15}$ Camac, M. “ $\mathrm{CO}_{2}$ Relaxation Processes in Shock Waves”. Fundamental Phenomena in Hypersonic Flow. J.G. Hall Ed. Cornell University Press. Pgs 195 - 215, 1964.

${ }^{16}$ Palmer, G.E. and Wright, M.J. “A Comparison of Methods to Compute High Temperature Gas Viscosity”. Journal of Thermophysics and Heat Transfer. Vol 17, no 2. Pgs 232 - 239. 2003.

${ }^{17}$ Palmer, G.E. and Wright, M.J. “A Comparison of Methods to Compute High Temperature Gas Thermal Conductivity”. AIAA Paper 2003-3913. Jun 2003.

${ }^{18}$ Gupta, R.; Yos, J.; Thompson, R.; and Lee, K. “A Review of Reaction Rates and Thermodynamic and Transport Properties for an 11-Species Air Model for Chemical and Thermal Nonequilibrium Calculations to 30000 K”. NASA RP-1232. August 1990.

${ }^{19}$ Ramshaw, J.D. “Self-consistent Effective Binary Diffusion in Multicomponent Gas Mixtures”. Journal of Non-Equilibrium Thermodynamics. Vol 15, no 3. Pgs 295 - 300. 1990.

${ }^{20}$ Baldwin, B.S. and Lomax, H. “Thin Layer Approximation and Algebraic Model for Separated Turbulent Flows”. AIAA Paper 78-0257. Huntsville, AL: 1978.

${ }^{21}$ Spalart, P.R. and Allmaras S.R. “A One-Equation Turbulence Model for Aerodynamic Flows”. AIAA Paper 92-0439. 30 ${ }^{\mathrm{TH}}$ Aerospace Sciences Meeting \& Exhibit. Reno, NV: 6-9 Jan, 1992.

${ }^{22}$ Menter, F.R. “Two-Equation Eddy-Viscosity Turbulence Models for Engineering Applications”. AIAA Journal. Vol 32, no 8. Pgs 1598 - 1605. August 1994.

${ }^{23}$ Brown, James. “Turbulence Model Validation for Hypersonic Flow”. AIAA Paper 2002-3308. ${ }^{\mathrm{TH}}$ Thermophysics and Heat Transfer Conference. St. Paul, MN: 24 - 26 Jun 2002.

${ }^{24}$ Catris S. and Aupoix B. "Improved Turbulence Models for Compressible Boundary Layers.” AIAA Paper 98-2696. $2^{\text {ND }}$ Theoretical Fluid Mechanics Meeting: Albuquerque, NM, June 1998.

${ }^{25}$ Mitcheltree, R. and Gnoffo, P. "Wake Flow About a MESUR Mars Entry Vehicle”. AIAA Paper 94-1958. 1994.

${ }^{26}$ Wright, M.J.; Olejniczak, J.; Brown, J.L; Hornung, H.G.; and Edquist, K.T. “Computational Modeling of T5 Laminar and Turbulent Heating Data on Blunt Cones, Part 2: Mars Applications”. AIAA Paper 2005-0177. 43 ${ }^{\mathrm{RD}}$ Aerospace Sciences Meeting \& Exhibit. Reno, NV: 10-14 January 2005.

${ }^{27}$ Hollis, B.R.; Liechty, D.S.; Wright, M.W.; Holden, M.S.; Wadhams, T.P.; MacLean, M.; and Dyakonov, A. “Transition Onset and Turbulent Heating Measurements for the Mars Science Laboratory Entry Vehicle”. AIAA Paper 2005-1437. 43 ${ }^{\text {RD }}$ Aerospace Sciences Meeting \& Exhibit. Reno, NV: 10-14 January 2005.

${ }^{28}$ Bonzel, H.P. and Ku, R. "Carbon Monoxide Oxidation on a Pt(110) Single Crystal Surface”. The Journal of Vacuum Science and Technology. Vol 9, no 2. Pgs 663-667. 1972. 
${ }^{29}$ Hiratsuka, K.; Kajdas, C.; and Yoshida, M. “Tribo-Catalysis in the Synthesis Reaction of Carbon Dioxide”. Tribology Transactions. Vol 47. Pgs 86 - 93. 2004.

${ }^{30}$ Stampfl, C. and Scheffler, M. "Mechanism of Efficient Carbon Monoxide Oxidation at Ru(0001)”. Journal of Vacuum Science and Technology A. Vol 15, no 3. Pgs 1635 - 1641. May/June 1997.

${ }^{31}$ Jenkins, D.R. and Voisey, M.A. "The Catalytic Reduction of Nitric Oxide in Automobile Exhaust Gases-II. The Kinetics of the Reactions of Carbon Monoxide with Nitric Oxide and/or Oxygen on an Oxidized Stainless-Steel Surface”. Atmospheric Environment. Vol 7, no 2. Pgs 187 - 199. Feb 1973.

${ }^{32}$ Wadhams, T.; MacLean, M.; Holden, M.; and Smolinski, G. "Return to Flight Testing of a 3.5\% Scale Space Shuttle OTS and OT Model at Mach Numbers of 3.5 and 4.0”. AIAA Paper 2006-0720. $44^{\mathrm{TH}}$ Aerospace Sciences Meeting \& Exhibit. Reno, NV: 9-12 January 2006.

${ }^{33}$ Wright, M.W. personal communication. 2006.

${ }^{34}$ Myerson, A.L. Interim Report on Transient Heat Transfer Measurements of Catalytic Recombination in a Step-function Flow of Atomic Oxygen. Cornell Aeronautical Lab (CAL) Report AF-1412-A-2. August 1962.

${ }^{35}$ Hartunian, R.A. and Thompson, W.P. Glow Discharge Shock Tube for Studying Surface Catalysis, Gas Phase, and Chemiluminescent Reactions. Aerospace Corp Report TDR-469(9240-01)-4. May 1965.

${ }^{36}$ Thompson, W.P. and Hartunian, R.A. "A Note of Caution on the Use of Catalytic Probes”. AIAA Journal. Vol 4, no 5. Pgs 957 - 959. May 1966. 